\title{
Da aplicabilidade à ação interventiva da BNCC da educação física escolar: em pauta
}

\section{o tema saúde}

\author{
From the applicability to the BNCC's interventive action in school physical education: the health \\ theme on the agenda
}

De la aplicabilidad a la acción interventiva de la BNCC en la educación física escolar: el tema de la salud en la agenda

Lorena Mota Catabriga

ORCID: https://orcid.org/0000-0001-9533-9303 Universidade Estadual de Maringá, Brasil E-mail: ra108234@uem.br

Catarina Messias Alves

ORCID: https://orcid.org/0000-0003-0434-2553 Universidade Estadual de Maringá, Brasil E-mail: catarina06alves@gmail.com

Ligiani Cordeiro dos Reis

ORCID: https://orcid.org/0000-0001-7164-9091 Universidade Estadual de Maringá, Brasil E-mail: ra116878@uem.br

Ana Luiza Barbosa Anversa

ORCID: https://orcid.org/0000-0003-4363-3433 Universidade Estadual de Maringá, Brasil E-mail: albanversa2@uem.br

Vânia de Fátima Matias de Souza ORCID: https://orcid.org/0000-0003-4631-1245 Universidade Estadual de Maringá, Brasil E-mail:vfmsouza@uem.br

\begin{abstract}
Resumo
Este estudo teve como objetivo analisar a configuração do tema saúde na BNCC e sua aplicabilidade no campo interventivo da Educação Física no Ensino Médio. Sustentado no método qualitativo do tipo descritivo, a investigação contou com a participação de 03 preceptoras do Programa Residência Pedagógica e 01 supervisora do PIBID. Como instrumento de coleta utilizou-se uma entrevista semiestruturada. Para análise dos dados optou-se pelos encaminhamentos descritos a partir da análise de conteúdo. Os resultados, evidenciaram que o tema saúde exposto na BNCC a necessidade de inclusão de temáticas específicas acerca dos conhecimentos e habilidades a serem tratados enquanto conteúdos da saúde nas aulas a partir das relações com as práticas corporais. Outrossim, evidenciou-se a carência no trato com os saberes e conhecimentos sobre o tema saúde, a partir da percepção das entrevistadas, sendo ressaltada pela necessidade de uma redistribuição estrutural em relação aos temas e conteúdos. Os dados amostrais, incidem sob a necessidade de discussão e reflexão acerca da relevância da temática no campo da Educação Física, expondo a necessidade da formação continuada dos professores, para além da efetiva necessidade de auto regulação e flexibilização dos documentos normativos a partir das necessidades educativas de acordo com a diversidade de realidade que compõe o universo escolar.
\end{abstract}

Palavras-chave: Políticas curriculares; Base nacional comum curricular; Saúde.

\begin{abstract}
This study aimed to discuss the health theme configuration in the BNCC and its applicability in the interventional field of Physical Education in High School. For that, the qualitative method of the descriptive type was used, the investigation had the participation of 03 preceptors of the Pedagogical Residency Program and a supervisor of PIBID. We rely on the analysis of the BNCC for High School, followed by a semi-structured interview with the preceptors and the supervisor. For data analysis, we opted for the referrals described from the content analysis. As a result, the need to include specific themes about the knowledge and skills to be treated as health content in the classes based on the relationships with bodily practices was evidenced on the health theme exposed in the BNCC. Furthermore, the lack of dealing with the knowledge and knowledge of the health theme was evidenced from the perception of the interviewees. In addition to this fact, the data collected in the interviews pointed to the need for a structural redistribution in relation to themes and contents, in this case, the health theme in the curricular matrix of Physical Education applied to High School. The sample data focus on the need for discussion and reflection on the relevance of
\end{abstract}


the theme in the field of Physical Education, in addition to highlighting the need for continued training of teachers, in addition to the effective need for self-regulation and flexibility of normative documents from the educational needs according to the diversity of reality that makes up the school universe.

Keywords: Curriculum policies; Common national curriculum base; Health.

\section{Resumen}

Este estudio tuvo como objetivo discutir la configuración del tema salud en la BNCC y su aplicabilidad en el campo de intervención de la Educación Física en la Enseñanza Media. Para eso, se utilizó el método cualitativo de tipo descriptivo, la investigación contó con la participación de 03 preceptores del Programa de Residencia Pedagógica y un supervisor del PIBID. Nos basamos en el análisis de la BNCC para la Enseñanza Media, seguido de una entrevista semiestructurada con los preceptores y el supervisor. Para el análisis de datos se optó por las referencias descritas a partir del análisis de contenido. Como resultado, se evidenció la necesidad de incluir temas específicos sobre los conocimientos y habilidades a ser tratados como contenidos de salud en las clases a partir de las relaciones con las prácticas corporales sobre el tema salud expuesto en la BNCC. Además, se evidenció a partir de la percepción de los entrevistados, la falta de manejo de los saberes y saberes del tema salud. Además de este hecho, los datos recogidos en las entrevistas apuntaron para la necesidad de una redistribución estructural en relación a temas y contenidos, en este caso, el tema salud en la matriz curricular de Educación Física aplicada a la Enseñanza Media. Los datos de la muestra se centran en la necesidad de discusión y reflexión sobre la relevancia del tema en el campo de la Educación Física, además de resaltar la necesidad de formación continua de los profesores, además de la necesidad efectiva de autorregulación y flexibilización normativa. documentos desde las necesidades educativas de acuerdo a la diversidad de realidad que conforma el universo escolar.

Palabras clave: Políticas curriculares; Base curricular nacional común; Salud.

\section{Introdução}

A Educação Física (EF) no contexto escolar, historicamente atrelada à perspectiva higienista, insere-se no ambiente escolar tendo como foco o aprimoramento das qualidades físicas e manutenção da saúde. Todavia, de acordo com os estudos realizados por Ferreira e Sampaio (2013), a Reforma Couto Ferraz de 1851 introduziu a EF nas escolas brasileiras, em 1882 Rui Barbosa por meio desta reforma definiu a ginástica como obrigatória, entretanto foi só a partir de 1920 que diversos estados colocaram a EF em suas reformas educacionais.

Sendo a EF um componente curricular, que apresenta em seu bojo as relações trazidas da/pela sociedade, sua ação interventiva no campo escolar, sucumbe a influências trazidas de cada tempo histórico e social da sociedade. Como conseguinte Ferreira e Sampaio (2013) em seu estudo apontam que a EF identificou sua prática na escola, sob a égide das perspectivas: Militarista, Pedagogicista, Competitivista, e Educação Física Popular. Cada momento da história tratado no campo da EF indicava uma relação social e econômica refletida nas ações educativas, tais como observava-se que abordagem higienista (até 1930) buscava-se a assepsia social, cuja centralidade e objetivo definia-se alicerçado pela preocupação para com a limpeza corporal e o tema saúde abordado indiretamente, além de levar uma visão biologicista e individualista. A abordagem militarista (1930 - 1945) buscava preparar alunos saudáveis por meio de exercícios militares e ginásticos para representar o Brasil em futuras guerras, mantinha-se uma visão biologicista da saúde, mas direcionado para a resistência e vigor físico. A tendência pedagogicista (1945 - 1964) inicia as discussões teóricas sobre o tema saúde para além da relação saúde doença, focada em uma formação higiênica e social. Na tendência Esportivista (1964 - 1985) a preocupação era em formar atletas, tendo a EF foco na fisiologia e nos treinamentos esportivos. Por fim, a tendência popular (iniciada em 1985) trouxe à tona a necessidade da discussão acerca dos temas da saúde, a partir do declínio do biologicismo, buscando enfatizar a EF como produtora da saúde e qualidade de vida (Ferreira et al., 2013).

A partir das discussões da tendência popular da EF, a área consolidou-se no contexto escolar, firmando-se como componente curricular por meio da Lei de Diretrizes e Bases da Educação Nacional (LDBEN) lei n. 9394/1996 (BRASIL, 1996). A partir desse momento os direcionamentos da Diretrizes visam organizar a estrutura da educação brasileira, propondo concepções, valores e finalidades. 
Outro documento que norteia os valores e finalidades da educação básica é o Plano Nacional de Educação, estabelecido pela Lei $\mathrm{n}^{\circ} 13.005$, traçando diretrizes, metas e estratégias para a política educacional entre o período de 2014 a 2024. Dentre as metas do Plano Nacional de Educação (PNE) evidenciou a necessidade da criação da Base Nacional Comum Curricular (BNCC) estruturado como um documento normativo que apresenta as competências, habilidades e as aprendizagens essenciais a serem desenvolvidos junto aos estudantes da educação básica.

Reitera-se que a BNCC, apresenta-se como documento orientador que na atualidade, define o conjunto de objetos de aprendizagens, competências e habilidades essenciais e gradativas que os estudantes devem desenvolver ao longo da educação básica. Para além desse fato, apresenta-se como parâmetro para a formulação dos currículos dos sistemas e de redes escolares, contribuindo para o alinhamento referente à formação dos professores, a avaliação, a elaboração de conteúdos educacionais, e ao critério para a oferta de infraestrutura adequada para o desenvolvimento da educação (BRASIL, 2018).

Posto este fato, os componentes curriculares do Ensino Médio são divididos em 5 grandes grupos, sendo: Linguagens e suas Tecnologias, Matemática e suas Tecnologias, Ciências da Natureza e suas Tecnologias, Ciências Humanas e Sociais Aplicadas e Formação Técnica e Profissional, que buscam promover um ensino dinâmico, com uma organização curricular e dos conteúdos programáticos de forma flexível, além de fazer com que o estudante tenha autonomia ao participar dessa mudança. Essa medida reforça que a construção de currículos e propostas pedagógicas atendam as especificidades locais e a multiplicidade de interesse dos estudantes, uma vez que tem-se a definição de que o Ensino Médio, a etapa final da educação básica, aponta para a necessidade de relacionar a formação humana atrelada aos sentidos e significados apresentados ao estudante em relação à sociedade e as suas estruturas sociais, colaborando para que o mesmo possa reconhecer o cenário no qual encontra-se inserido como uma estrutura complexa, dinâmica e fluida, que carece de olhares e direcionamentos comprometidos para com suas necessidades individuais e coletivas.

Nesse cenário a Educação Física (EF), enquanto componente curricular, inserida no campo de Linguagens e suas Tecnologias, cujos pressupostos estão ligados a ampliação da autonomia, protagonismo e autoria nas práticas de diferentes linguagens, na identificação e na crítica aos diferentes usos dessas linguagens. Entretanto, a EF, colocada como uma prática facultativa aos estudantes, mas consta a possibilidade dos estudantes explorarem o movimento e a gestualidade em diferentes práticas corporais de diferentes grupos culturais, além de analisar os discursos e valores associados a eles, estimulando o desenvolvimento da curiosidade intelectual da pesquisa, da capacidade e da argumentação.

Ao buscar propositivas sobre a temática saúde na BNCC, torna-se possível perceber que a intenção do documento posto, explicita a necessidade dos estudantes experienciaremos conteúdos das práticas corporais produzidos historicamente pela sociedade, enfatizando que os mesmos devem buscar aprofundar seus conhecimentos sobre o corpo humano e suas potencialidades, além de entenderem a importância de assumir um estilo de vida ativo, e os componentes do movimento relacionados à manutenção da saúde, para que desse modo desenvolvam um cuidado com o corpo e a saúde (BRASIL, 2018).

Entretanto, os estudos realizados evidenciam a escassez dos conteúdos escolares, por vezes restritos ao campo da prática de esportes relacionados aos conhecimentos oriundos das práticas corporais relacionadas aos esportes de invasão e de rede. Esse impasse evidenciado observado na estrutura organizacional da escola, e replicado na organicidade pedagógica dos Programas Residência pedagógica e Programa Institucional de Bolsas de Iniciação Docência (PIBID). (Monteiro et al. 2020)

Frente ao exposto a pesquisa realizada teve como objetivo analisar a configuração do tema saúde na BNCC e sua aplicabilidade no campo interventivo da Educação Física no Ensino Médio.

\section{Metodologia}

A presente pesquisa adotou o método qualitativo do tipo descritivo. A pesquisa qualitativa envolve uma abordagem interpretativa do mundo, seus pesquisadores estudam as coisas em seus cenários naturais, tentando entender os fenômenos em 
termos dos significados que as pessoas a eles conferem (AUGUSTO et al. 2013). Já o caráter descritivo visa trazer as características de determinada população ou fenômeno, ou ainda o estabelecimento de relações entre variáveis (GIL, 2002).

Nessa perspectiva a pesquisa se dividiu em dois momentos: a) estado do conhecimento acerca do tema saúde na Educação Física (EF) aplicada ao Ensino Médio (EM), b) Pesquisa de campo por meio de uma entrevista semiestruturada com as três professoras preceptoras da Residência Pedagógica e uma professora do Programa Institucional de Bolsas de Iniciação a Docência de Maringá - PR.

Para a escolha da amostra da pesquisa, buscou-se aproximações entre os professores que atuam na educação básica e possuem aproximações com a Universidade. Para tanto, chegou-se aos Programa de formação inicial de Professores PIBID e RP. Monteiro (2020) aponta que o Programa Residência Pedagógica concede bolsas para discentes ativos do curso de licenciatura e que tenham cursado pelo menos $50 \%$ da graduação e busca ofertar ao aluno residente competências que permitam realizar um ensino de qualidade nas escolas da educação básica. Já o Programa Institucional de Bolsas de Iniciação à Docência concede bolsas para discentes de cursos presenciais de licenciatura e que estejam cursando a primeira metade da graduação e tem como intuito aproximar e incentivar os futuros docentes a trabalharem na educação básica. Na Universidade Estadual de Maringá - UEM esses programas abrangem diversos cursos, entre eles o curso de Educação Física, foco deste estudo. Os programas contam com duas professoras coordenadoras da área e quatro professoras preceptoras que atuam em colégios da rede estadual da cidade de Maringá-PR, essas quatro professoras preceptoras serão selecionadas para realizar a entrevista acerca do tema estudado. Para tanto, optou-se em realizar uma pesquisa com esse grupo de professores por atuarem na prática cotidiana da escola, além de participar de um programa de formação de professores.

Tendo a estruturação amostral, optou-se por utilizar como instrumento de coleta a entrevista semiestruturada, isto porque, segundo Gil (2011) a entrevista é uma forma de diálogo assimétrico, em que uma das partes busca coletar dados e a outra se apresenta como fonte de informação. Sendo assim as perguntas foram elaboradas a partir de uma matriz analítica, visando os objetivos traçados para a pesquisa, que levam em consideração: o contexto da EF escolar, as relações estabelecidas entre o professor preceptor da RP e o aluno residente e os conteúdos da saúde trabalhados por esse professor.

\section{Coleta de dados}

As entrevistas foram semiestruturadas para facilitar e guiar os diálogos, entretanto como Gil (2011) afirma esta entrevista seguiu com um caráter de diálogo sendo assimétrico, ou seja, não possuiu um caráter rígido e assim deu liberdade para as professoras se sentirem mais à vontade com a entrevista. As professoras foram convidadas para participar das entrevistas por meio de uma mensagem enviada via Whatsapp, em razão do ensino hibrido adotado no ano de 2021 , tendo as redes sociais evidenciando-se como sendo um potencial comunicativo, e ter sido uma possibilidade de coleta acessível junto a amostra. Definido a forma de coleta, o passo seguinte foi contatar as participantes do estudo na qual as mesmas aceitaram mediante termo de consentimento livre e esclarecido de acordo com as deliberações da aprovação Comitê Permanente de Ética em Pesquisa com Seres Humanos da Universidade Estadual de Maringá, sob parecer n. 4.501.175. Na sequência, para a realização das coletas agendou-se os horários das mesmas de acordo com a disponibilidade das professoras e das pesquisadoras. Tendo o agendamento posto, optou-se por realizar as entrevistas foram realizadas via a plataforma Google Meet, estas foram gravadas e arquivadas no drive das pesquisadoras para fins acadêmicos e científicos apenas. Ressalta-se que no início de cada entrevista as professoras foram informadas que poderiam tirar dúvidas a respeito da pesquisa no geral e que poderiam recusar-se a responder a qualquer questão da entrevista ou até mesmo desistir da entrevista em qualquer momento, assim como, poderiam se recusar a responder alguma questão sem que isto acarreta-se ônus ou prejuízo à sua pessoa. 


\section{Transcrição e categorização dos dados}

Após a realização das entrevistas foi realizada a transcrição delas para fins de categorizar as entrevistas e analisar os resultados obtidos nelas. Para a categorização elas foram divididas em três grandes categorias como mostra a Figura 1, a seguir.

Figura 1 - Fluxograma da categorização das entrevistas.

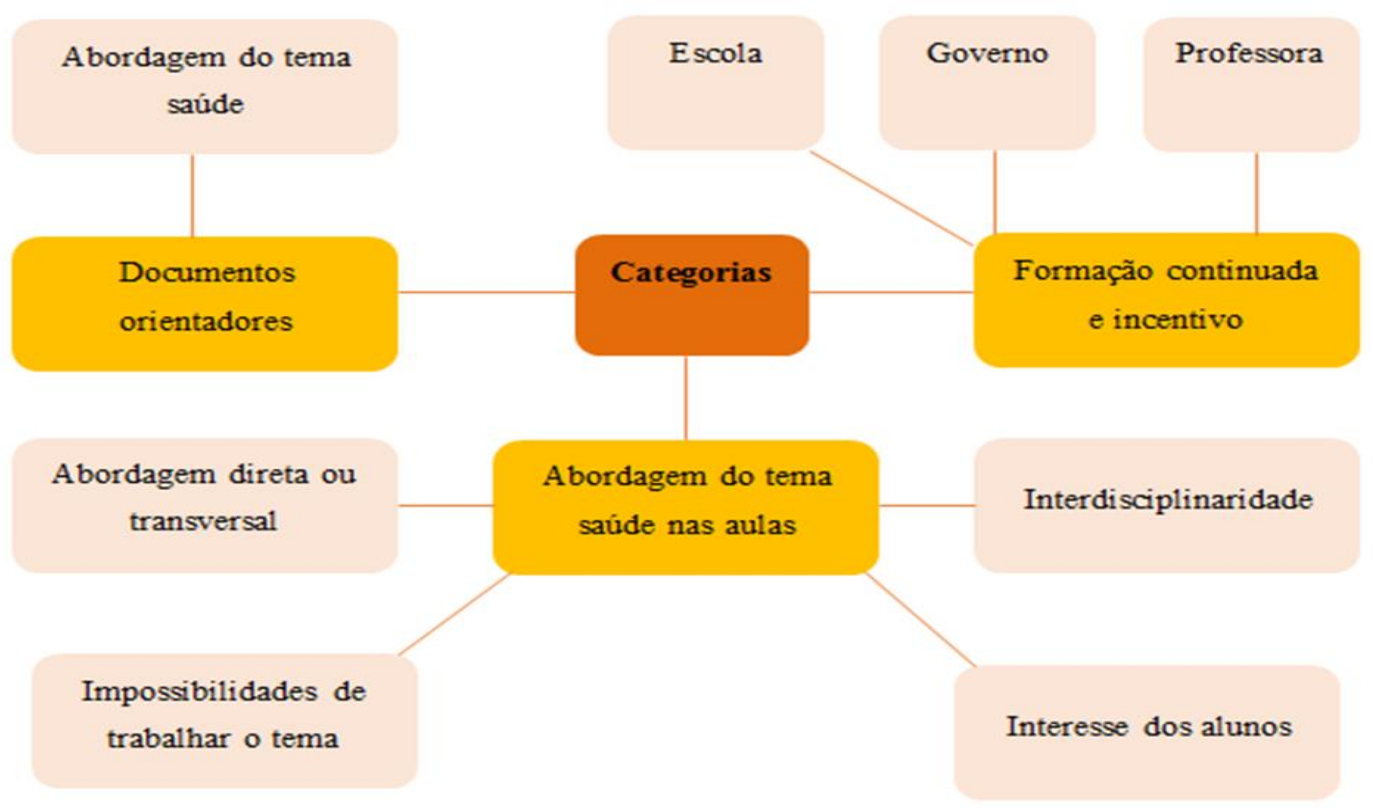

Fonte: Autores.

A primeira categoria foi para entender quais os documentos que as professoras utilizavam como base no momento do planejamento de suas aulas, bem como entender de que forma os documentos citados abordam o tema saúde. A segunda categoria foi na busca de compreender de que forma o tema saúde é abordado nas aulas de Educação Física, ou seja, se o tema é tratado direta ou indiretamente, se existem impossibilidades ao se trabalhar esse tema, se há um trabalho interdisciplinar para se abordar a saúde e qual o nível de interesse dos alunos. E a terceira categoria buscou compreender se essas professoras possuíam incentivo ou buscavam ter uma formação continuada, seja esse incentivo por parte da escola ou governo. E a partir dessa categorização foi realizada a análise dos resultados tendo como base os artigos selecionados na Revisão Integrativa.

\section{Resultados e Discussão}

\section{Perfil dos respondentes}

Para fins éticos as professoras tiveram seus nomes e identidades protegidos e dessa forma para a discussão dos resultados as professoras foram referenciadas por meio de números que seguem a ordem que foram feitas as entrevistas, ou seja, por se tratar de quatro professoras estas foram identificadas como Professora 01, Professora 02, Professora 03 e Professora 04.

Verificou-se que em unanimidade todos os docentes entrevistados e que participam do RP e PIBID são do sexo feminino o que demonstra um avanço feminino nesta área. Constatou-se que todas as professoras participantes das pesquisas possuem pós-graduação latu sensu, além da efetiva participação em projetos e cursos de extensão, vale aqui ressaltar que a Professora 02 possui mestrado e doutorado na área de educação. Em relação à experiência na docência, as participantes 
apresentaram um tempo médio de trabalho com a Educação Física Escolar de \pm 21,2 anos. Além disso, as Professoras 02 e 03 tiveram anteriormente a sua prática na educação experiência em uma clínica fisioterápica e academias respectivamente. O desenho biográfico da amostra, incide na representação das relações entre o campo da prática e as incursões no campo teórico e de estudos na área, para além de disponibilizarem indícios acerca da construção identitária das professoras participantes.

\section{Documentos orientadores e a saúde na íntegra}

A BNCC afirma que no Ensino Médio apresenta a necessidade de consolidar os conhecimentos adquiridos no decorrer de toda a formação do aluno. Nessa fase da educação, o jovem articula sua realidade social aos seus conhecimentos e saberes, além de dar início à um aprofundamento no conhecimento sobre si mesmo. Visando auxiliá-los a BNCC busca oferecer uma formação mais integral e na área de linguagens e suas tecnologias objetiva-se disponibilizar possibilidades de uma participação mais plena dos jovens nas diferentes práticas socioculturais que envolvem a linguagem, podendo ela ser artística, corporal ou verbal e por meio dessas linguagens os jovens, que já compreendem melhor as abstrações, podem aprofundar-se nas reflexões a respeito do mundo dando início a uma participação mais ativa na produção cultural e na vida pública. E segundo a BNCC o papel da Educação Física na área das linguagens e suas tecnologias é

Possibilitar a exploração dos movimentos e da gestualidade em práticas corporais de diferentes grupos culturais e analisar os discursos e os valores associados a elas, bem como os processos de negociação de sentidos que estão em jogo na sua apreciação e produção (BRASIL, 2018, p. 483).

Busca-se proporcionar aos estudantes experiências de novos jogos e brincadeiras, esportes, danças, lutas, ginásticas e práticas corporais de aventura, porém diferentemente do Ensino Fundamental esses conteúdos visam agora fazer com que os jovens venham a entender a importância dessas práticas para a saúde, além de dar a eles um maior conhecimento de suas capacidades e habilidades corporais. Com isso a Educação Física busca ir além de apenas a conscientização corporal, ela objetiva fazer com que os estudantes possam compreender alguns de seus direitos e deveres na sociedade, podendo dessa forma a Educação Física articular-se com as demais áreas do conhecimento e permitindo que esses estudantes além de saber como fazer suas práticas corporais compreendam as relações atitudinais, conceituais, culturais e sociais que abarcam a realização dessas práticas, compostas por sua trajetória histórica e social. A área da linguagem e tecnologia pretende preparar esses estudantes para viverem em sociedade permitindo a eles desenvolverem processos de tomadas de decisão e assumir posições conscientes e reflexivas de forma a se tornarem cidadãos democráticos ativos dentro da sociedade. Por meio disto aproximamos esses alunos cada vez mais á suas possíveis áreas de trabalho, de vida acadêmica e de vida social tornando-os cidadãos conscientes, reflexivos e ativos dentro da sociedade e permitindo que seus planos e sonhos tomem uma maior amplitude através da visão das diversas possibilidades estéticas e éticas que lhes são dadas.

Para que tais objetivos sejam alcançados de forma concreta observa-se ser necessário que os professores tragam elementos visuais, sonoros, verbais e corporais, incorporando às suas aulas as novas Tecnologias Digitais da Informação e Comunicação (TDIC). Com a inclusão dessas TDICs nas escolas surge a necessidade dos professores da área da linguagem trazerem reflexões sobre as novas formas de comunicação, bem como, a forma ética de se agir com tais tecnologias orientando seus alunos a respeito dos riscos que estão presentes nessas TDICs e os professores devem estar incentivando-os a não serem meros consumidores dessas tecnologias, mas sim produtores dessas novas formas de linguagem.

Tendo em vista a abordagem da BNCC no Ensino Médio, buscando não influenciar nas respostas das professoras questionou-se as professoras acerca de quais documentos recorreram para estruturar e organizar sua ação didática-pedagógica. Entre as respostas, evidenciou-se que as participantes fazem uso de diversos documentos para a estruturação de suas aulas, outrossim evidenciou-se que a BNCC não apresentou-se como documento basilar para a estruturação das aulas de apenas pela 
professora 01. Entre os documentos citados estão o Referencial Curricular do Paraná, o Currículo da Rede Estadual Paranaense (CREP) e o Projeto Político Pedagógico (PPP). Tais documentos agem como adaptadores da BNCC para a realidade do Estado e da escola e por isso faz-se necessário uma breve explanação sobre cada um deles.

A proposta do Referencial teórico do Paraná surgiu após a aprovação da BNCC pelo Conselho Nacional de Educação em dezembro de 2017, na qual notou-se uma necessidade de todos os Estados e municípios do país formularem um documento que fosse referência para o seu território e que estivesse alinhado com o documento da BNCC. Portanto, com a constituição do Comitê Executivo e Assessoria Técnica se deu início ao Referencial Curricular do Paraná, que é um documento Estadual que norteia a elaboração ou reelaboração dos currículos de escolas municipais e estaduais, públicas ou privadas do Paraná. Permitindo assim, um ensino elaborado de acordo com a realidade local, social e individual da escola e do estudante. É a partir deste documento que se estabelece os direitos e os objetivos de aprendizagem nas etapas da Educação Infantil e do Ensino Fundamental com o intuito de trazer um ensino de qualidade, igualdade e equidade para todos os estudantes (PARANÁ, 2018). Porém, neste documento não consta o Ensino Médio por conta de este ainda estar em fase de construção.

O Referencial Curricular do Paraná possui a mesma organização da BNCC, entretanto este se adapta à realidade paranaense. Neste documento busca-se entender os princípios e direitos estabelecidos para a construção de um currículo na qual possua transições entre as etapas do Ensino Infantil, anos iniciais e anos finais do Ensino Fundamental.

A respeito do tema saúde na educação física o Referencial Curricular traz que é um direito de aprendizagem do estudante se auto conhecer e saber cuidar e apreciar de sua saúde física e emocional, compreender-se como um ser humano individual que faz parte de uma sociedade, repleta de diversidade, que reconhece tanto suas emoções quanto às emoções alheias, aprendendo assim a lidar com elas (PARANÁ, 2018). Os dados analisados evidenciam a inexistência de uma preocupação tanto no que se refere a saúde física como a saúde psicológica. Além disso, o documento retrata a saúde como um tema intrínseco nas unidades temáticas sempre tentando relacionar o exercício e suas causas e efeitos na saúde. Porém, o tema saúde está sempre intrínseco nas unidades temáticas e campos de experiência de forma que se trabalhe não somente as questões fisiológicas do corpo humano, como também, questões relacionadas à saúde mental.

Outro documento que as professoras entrevistadas informaram refere-se o Currículo da Rede Estadual Paranaense (CREP). Documento este que foi consolidado em 2021 com o intuito de ser um orientador para a construção da Proposta Pedagógica Curricular (PPC), sendo assim, um complementador do Referencial Curricular do Paraná, que traz para os professores um norte para selecionarem os conteúdos que atendam os direitos e necessidades dos estudantes. Porém, diferente dos documentos citados anteriormente, o CREP restringe-se a rede estadual, ficando as redes de ensino municipais e privados orientandas por seus documentos orientadores que estruturam a base curricular dos anos iniciais e finais do Ensino Fundamental, excluindo desta forma o Ensino Infantil e Ensino Médio. O CREP auxilia os professores não só na escolha da proposta pedagógica, como também nas avaliações para ver se os objetivos de cada temática foram atingidos. Neste documento a saúde apresenta-se na área de autoconhecimento e autocuidado sendo essa saúde não apenas física, mas também emocional. E assim como no Referencial Curricular do Paraná o tema saúde aparece de forma intrínseca no documento, nas unidades temáticas.

Compreendendo a relevância do Projeto Político Pedagógico (PPP), uma vez que este apresenta-se como sendo um documento essencial e indispensável no âmbito escolar tendo em vista que este documento irá nortear o trabalho pedagógico da escola. Sendo assim, cada escola possui seu próprio PPP adequando-o para a realidade social, cultural, local e individual de cada unidade escolar. Portanto, segundo Veiga (2013, p. 163) o

[...] projeto pedagógico constituído pela própria comunidade escolar é o definidor de critérios para a organização curricular e a seleção e estruturação dos conteúdos, das metodologias de ensino, dos recursos didáticos e tecnológicos e da avaliação. 
Este documento possui caráter político, pois visa fazer a articulação e comunicação entre a realidade das necessidades da sociedade e o dever sociopolítico da escola. E torna-se pedagógico, pois tem o interesse de cumprir o dever de formar cidadãos transformadores de sua realidade. Conquanto, a partir do exposto o PPP não deve ser entendido como mais um documento qualquer que está lá apenas para cumprir obrigações burocráticas. Este documento é uma análise da realidade do presente na busca de projetar um futuro melhor e dessa forma há a necessidade de o corpo docente, a sociedade civil e os alunos e familiares participarem da construção desse documento assumindo assim um caráter de contrato social (VEIGA, 1998, p. 12). Por esse documento ser individual para cada escola não surgiu a necessidade de averiguar o tema saúde dentro desses, tendo em vista que o nosso objetivo aqui é apenas esclarecer quais são os documentos mencionados pelas professoras, pois a pesquisa é voltada para a BNCC com foco no Ensino Médio e dessa forma nos focaremos nela.

Nas entrevistas com roteiros semiestruturados, questionou-se as professoras acerca da necessidade do planejamento de suas aulas. Todas afirmaram ser necessário, porém a Professora 03 afirmou fazer o planejamento anual e trimestral, dizendo ainda que

"na escola é obrigatório esse planejamento e isso é institucionalizado [...] é uma atribuição ao professor de todo início de trimestre planejar as suas aulas".

A referida professora entrevista, reiterou ainda que embora o planejamento seja um documento obrigatório a ser cumprido, a mesma observa a irrelevância da preparação de aula. Afirma ainda que o planejamento torna-se necessário apenas ao considerar -se o conteúdo a ser aplicado apresenta falta de domínio e habilidades para a aplicabilidade não é de seu domínio. Já as demais professoras afirmaram fazer um planejamento para cada aula.

A professora 01 salientou ainda a importância de haver uma comunicação entre os professores de Educação Física da escola, pois nas escolas públicas principalmente em relação ao Ensino Médio a inexistência de um trabalho contínuo entre as turmas porque todo ano um professor diferente assume a turma na qual a professora deu aula. Tornando assim a continuidade dos conteúdos muito difícil sem antes ter uma prévia do que o professor anterior passou e o que o professor do próximo ano irá passar para os estudantes. Salientou ainda que na escola em que trabalha sempre busca no momento de planejamento conversar com os professores dos anos anteriores e anos seguintes e alinhar seus conteúdos de forma que haja uma continuidade nos conteúdos passados. Processo esse que está de acordo com Filho e Valente (2017) quando estes afirmam que a Educação Física necessita de um trabalho contínuo sem interrupções, permitindo assim que os alunos se desenvolvam fisicamente de acordo com suas idades, seu peso e altura.

Em questão aos documentos utilizados para realizarem esses planejamentos sejam anuais, trimestrais ou por aula, somente a Professora 01 desconsiderou a BNCC como documento orientador de seus planejamentos, conquanto ela foi a única professora a citar o Referencial Curricular do Paraná e como já discutido anteriormente vale salientar que este documento é uma adaptação da BNCC para a realidade local, social e cultural de cada Estado. Em relação ao CREP apenas as Professoras 01 e 03 afirmaram utilizar esse documento afirmando que por possuir uma adaptação da BNCC ele auxilia na seleção de quais conteúdos aplicar. E, por fim, o Projeto Político-Pedagógico foi citado apenas pelas Professoras 02 e 03, na qual a Professora 03 expressou a importância do PPP desde as questões metodológicas até o fato de o Programa Institucional de Bolsas de Iniciação à Docência (PIBID) e Residência Pedagógica (RP) existirem dentro dos colégios como meio de permitir aos acadêmicos, que serão os futuros docentes, a fazerem uma imersão em sua futura profissão.

Tendo explicado e exposto tais pontos, faz-se necessário um olhar atento para a falta de manuseio e utilização desses documentos pelas professoras e que aqui foram explicados. Pois esses documentos são complementares e fazem entre si uma interlocução que auxilia e facilita a organização dos conteúdos a serem trabalhos em sala de aula e em quadra, sendo assim constatou-se uma falta de conhecimento por parte das docentes sobre esses documentos norteadores que embora não possuam 
um caráter prescritivo (PAIVA et al., 2017) dão suporte para a seleção dos conteúdos e possibilitam a adaptação para a realidade da escola.

Entretanto as professoras argumentaram que os documentos apresentados na entrevista tratam o tema saúde de uma forma muito superficial em que o professor fica à mercê de ditar aquilo que é ou não importante para os alunos. Mas de acordo com Paiva et al. (2017, p.11) os documentos curriculares existem para oferecer "sugestões ou indicativos de conteúdos, a partir das intencionalidades". Visto isso, é válida a desorientação das professoras sobre o tema saúde entendendo que se trata de um tema muito amplo e, que a BNCC um documento orientador, ainda apresenta nebulosidade aos docentes acerca de orientações específicas, entretanto não prescritiva, sobre quais áreas da saúde abordar, visto a abrangência desse tema e que além da Educação Física outras disciplinas também tem o dever de orientar sobre as questões desse tema.

Posto a situação, faz-se aqui uma indagação: seria viável a implementação da saúde como Unidade Temática na BNCC e nos documentos que a ela se adaptam? Visto que trata-se de tema amplo e entendendo que no Ensino Médio os alunos estão em uma fase de conhecimento e de identificação, faz-se muito importante a abordagem desse tema de forma que estes alunos ao saírem da escola sejam cidadãos ativos com senso crítico e reflexivo a respeito de sua própria saúde e através dessa conscientização irá se almejar obter benefícios no combate de doenças transtornos e síndromes que podem ser evitados e trabalhados através desses conhecimento disponibilizados.

\section{Estratégia docente ao tratar da saúde na Educação Física}

O tema saúde por ser tratado pela BNCC de forma muito ampla, permite que os professores interpretem a realidade social, econômica e local que os alunos estão inseridos permitindo assim uma abordagem do tema de forma que esses alunos retenham esse conteúdo e saiam do Ensino Básico preparados para serem agentes ativos de sua realidade. Portanto, indagou-se a

s professoras o que seria esse tema saúde que estas abordam em suas aulas. E em relação ao Ensino Médio as professoras afirmaram que os alunos, que encontram-se em fase de conhecimento e exploração corporal, começam a se interessar muito por questões de academia, doenças associadas à falta de exercício, cuidado corporal, alimentação, uso de drogas, anabolizantes e questões emocionais.

[...] se fala sobre alimentação, drogas, anabolizantes, suplementos [...] Gosto de conversar com o $2^{\circ}$ ano sobre uma alimentação saudável de como está a qualidade de vida e aí eles vão falando (Professora 01).

[...] sempre voltado para o movimento [...] para atividade física [...] Nisso tem qualidade de vida, tem frequência cardíaca durante um exercício, têm as formas de você modificar os exercícios como intensidade frequência, etc. [...] (Professora 02).

[...] aspectos físicos e aqueles fisiológicos dos sistemas relacionados ao sistema circulatório [...] toda a questão muscular articular e sempre é citado aqueles aspectos psicológicos e emocionais por conta da liberação da endorfina e os benefícios que ela traz para o nosso organismo [...] (Professora 03).

Eles amam quando falam sobre a questão de anabolizantes e suplementos [...] (Professora 04).

Nas questões alimentares Schuh et al. (2017) em sua pesquisa sobre a prevenção de ganho de peso em crianças afirmam que pela escola participar do processo de formação de princípios dos estudantes esta faz-se necessário para a elaboração do tema saúde de forma que o estudante se torne um sujeito crítico a respeito de seus hábitos alimentares e entenda os riscos que a alimentação incorreta poderia acarretar em sua vida.

Outrossim, evidenciou-se um tratamento superficial de conteúdos que trabalhem as questões de transtornos alimentares e que tragam questionamentos e críticas sobre as ditaduras estéticas que os meios de comunicação têm imposto para a população e principalmente para os jovens. Tendo em vista que esses alunos, segundo Silva (2017), estão em uma fase de reconhecimento de si, buscando se sentirem pertencentes a um grupo, moldando sua personalidade e comportamento. 
Fatores estes que estão diretamente relacionados ao ambiente em que estão inseridos, sendo a escola o local onde costumam passar boa parte de seus dias. Dessa forma, faz-se de extrema importância orientar e alertar os alunos sobre essas influências de padrões sociais pré-existentes que podem por meio da ênfase deliberada pela mídia e redes sociais sobre a pressão dos padrões de beleza e comportamentos acabar culminando em doenças, síndromes e transtornos psíquicos. Com isso, esses temas acabam tornando-se por vezes subjetivos apresentando lacunas de conhecimentos que podem inferir em problemas subsequentes no cotidiano da vida dos estudantes. Corrobora com essa afirmativa os autores Dias, Souza e Oliveira (2020) quando afirmam que por esses temas e outros relacionados não serem abordados na Educação Física os estudantes possuem um entendimento errôneo sobre tais assuntos e assim acabam causando danos em sua saúde.

Sabendo que todas as professoras entrevistadas tiveram experiências docentes com o Ensino Fundamental questionouse acerca dos conteúdos abordados eram os mesmos e estas afirmaram que não, pois no Ensino Fundamental o tema saúde volta-se para questões da anatomia, funcionalidade dos músculos e de forma superficial a respeito de primeiros socorros.

[...] no ensino fundamental é mais voltado em relação à primeiros socorros, em como saber uma questão de fratura de entorse [...] Mas assim a função dos músculos no exercício, mas não tão aperfeiçoado quanto é no Ensino Médio. O ensino médio [...] é mais a saúde do que os conteúdos estruturantes eles vão encaixando ali dentro dos conteúdos estruturantes e no ensino fundamental é o contrário (Professora 02).

Nas entrevistas a partir do roteiro semiestruturado as professoras foram questionadas se abordavam o tema saúde de forma transversal ou direta e constatou-se uma dualidade nas abordagens desse tema de forma que a Professora 01 relatou preferir trabalhar o tema diretamente e afirmou que geralmente o interesse e a proposta do tema surge em conversas sobre os temas estruturantes como o esporte e nisso os alunos demonstram um interesse pelo assunto e dessa forma a professora estrutura uma aula para falar sobre as questões levantadas pelos alunos.

[...] eu gosto de trabalhar de forma direta assim você tem que planejar pesquisar e se organizar para aquela aula, nas muitas vezes as aulas começam em uma conversa informal dentro de um conteúdo lá do esporte (Professora 01).

Os dados coletados junto as demais professoras afirmaram tratar sobre o tema saúde de forma transversal aos conteúdos estruturantes como a luta, a dança, o esporte e a ginástica, tendo em vista que a BNCC e todos os outros documentos por elas citados não apresentam o tema saúde como um conteúdo estruturante e sim sempre de forma transversal que conforme Paiva et al. (2017) afirmam que os temas proporcionam uma abertura para o professor que poderá problematizar as diferentes situações e os diferentes contextos que estes temas podem trazer no decorrer de suas explanações e com isto surge entre os temas a saúde e suas relações com o tema proposto. As professoras que afirmaram tratar o conteúdo de forma transversal relataram que o tema mais fácil de se introduzir a temática saúde são os conteúdos de ginástica.

[...] você procura dentro do conteúdo abordar as questões da Saúde geralmente é no conteúdo da ginástica que aonde a gente consegue encaixar. Na dança por exemplo você vai ter coisas mais superficiais em relação à saúde ela entra com um benefício, mas o que aprofunda mesmo é no tema da ginástica. (Professora 02).

[...] senti que quando eu trabalhei a ginástica de conscientização corporal deu para gente trabalhar de uma forma mais evidente [...](Professora 03)

[...] sempre trabalha ele aplicando em outros conteúdos como o esporte, a dança, à luta e nisso você vai demonstrando por que é importante você praticar essas atividades físicas [...] (Professora 04).

Ao serem indagadas sobre o interesse dos estudantes em relação ao tema saúde houve uma unanimidade da parte das professoras quando afirmaram que é de grande interesse dos alunos do Ensino Médio falarem sobre essas questões. Afirmaram 
que por se tratar de um conteúdo que está diretamente ligado a realidade desses alunos e ao seu cotidiano eles demonstram interesse, perguntam e interagem com as professoras proporcionando assim um sistema de educação na qual o professor não é visto como o detentor de conhecimento e dessa forma há uma troca de saberes entre os estudantes e os professores. Entretanto, comparando o Ensino Fundamental com o Médio as professoras afirmaram que não há um interesse tão grande por parte dos alunos do Fundamental.

\section{Nossa totalmente eles são super interessados (Professora 01).}

No Ensino Fundamental como o assunto é uma coisa mais voltada para primeiros socorros, para higiene, etc., eu não vejo muito interesse não, mas no Ensino Médio sim (Professora 02).

\section{Bastante [...] (Professora 03).}

[...] eles gostam bastante desse tema e se instigam em assuntos da saúde e havia bastante interesse neles muita curiosidade (Professora 04).

Outro dado evidenciado, f problematizado nas entrevistas se haviam impossibilidades para se trabalhar o tema saúde na escola e se constatou diferentes respostas. As professoras 01 e 02 argumentaram a respeito da falta de material, a utopia dos documentos orientadores ao proporem práticas corporais que fogem da realidade escolar tornando os conteúdos muito teóricos e relataram ainda a falta de um livro didático de Educação Física. Uma dificuldade apontada pela Professora 02 foi a questão de não possuir conhecimento sobre um determinado conteúdo, entretanto esta afirmou que isso cabe ao professor se preparar e estudar aquele conteúdo pelo qual não possui tanta maestria. As professoras 03 e 04 afirmaram que não veem limitações para se tratar desse tema embora, haja limitações em questão de aprofundamentos, por conta de tempo de aula e quantidade de conteúdo.

Dentro dessa questão de impossibilidades de se tratar desse tema e por esta pesquisa ter sido realizada durante a pandemia do COVID-19 (COVID por conta do nome do vírus Corona Virus Disease, enquanto “19” se refere a 2019) entendeu-se necessário a compreensão de se os alunos têm demonstrado mais interesse nesse tema saúde devido a pandemia, concluindo que com a inserção do Ensino Remoto Emergencial (ERE) as aulas de Educação Física ficaram mais limitadas contendo muito mais teoria do que prática. As Professoras 02 e 03 afirmaram que os alunos têm demonstrado mais interesse pelo tema saúde, pois antes o tema era empregado de forma transversal aos conteúdos estruturantes como a dança, ginástica, esporte e lutas e a teoria ficava um pouco mais subentendida. Entretanto com a pandemia as práticas corporais ficaram complicadas de serem aplicadas e por conta desse vírus ser um caso que afeta a saúde o assunto se tornou mais recorrente e por isso os alunos estão procurando entender mais sobre esse tema e demonstram um interesse maior agora que se tem focado na teoria. A professora 03 ainda salientou o fato de a pandemia de certa forma ter valorizado a Educação Física, uma vez que os estudantes apresentaram valorização acerca de que os conteúdos Educação Física não é um momento apenas para sair da sala, mas sim uma disciplina que tem muito a acrescentar aos mesmos.

As Professoras 01 e 04 discorreram sobre a dificuldade que está sendo dar aula nesse ERE, pois adicionou-se muitos deveres aos professores. Porque muitos alunos não possuem acesso à internet e a tecnologias para estarem presentes nas aulas e para não serem tão prejudicados estes alunos pegam o material resumido e impresso o que precariza a educação e demanda mais trabalho para os professores visto que estes têm que dar conta das aulas online e das aulas impressas e para além disso ainda tem a relação de que no ERE muitos alunos não participam das aulas e nem mesmo abrem as câmeras ou não possuem câmeras e por isso torna-se extremamente difícil para os professores avaliarem quem de fato está presente na aula e se de fato os alunos estão entendendo o que está lhe sendo passado. 
Além das impossibilidades enfrentadas pelas professoras, buscamos entender se estas faziam uso da interdisciplinaridade que em concordância com Fazenda (2010, apud. FILHO; VALENTE, 2017), propõe que nenhuma disciplina é independente e portanto é necessário que haja uma comunicação entre essas disciplinas para que o processo de aprendizagem seja abordado de forma como um todo, podendo assim, o aluno se tornar um agente transformador de sua sociedade que o cerca através de uma estruturação e permita que façam essas associações entre as disciplinas, mas também entre os saberes oferecidos pela escola com o seu cotidiano. Os dados indicaram que os temas são abordados nas aulas, entretanto por vezes de forma superficial. Em relação ao trabalhado com interdisciplinaridade, a Professora 04 afirmou inexistência na relação do conteúdo saúde junto a outras disciplinas tais como biologia, física e outras áreas. As demais professoras afirmaram já terem trabalhado com a interdisciplinaridade. Sendo que as Professoras 01 e 02 afirmaram trabalhar com a interdisciplinaridade trazendo profissionais da saúde para explanar um pouco sobre o tema saúde e afirmaram que por ter especialistas da área para discorrer sobre o assunto os estudantes se sentem instigados e animados a participarem de diálogos para entenderem melhor sobre o assunto.'

Ainda em relação a interdisciplinaridade as Professoras 02 e 03 afirmaram já ter trabalhado a interdisciplinaridade com as disciplinas de biologia, ciências e português, entretanto a Professora 02 afirmou que a interdisciplinaridade apresentase uma ação pedagógica complexa e trabalhoso, pois faz-se necessário que os professores de ambas as disciplinas coloquem seus cronogramas em pareamento de forma que não divirjam nas informações e que andem em um consenso e por isso demanda muito tempo. Por esse fator, afirmou não trabalhar mais a interdisciplinaridade, pois para os planejamentos pedagógicos é dado aos professores apenas uma semana na qual precisam tratar de assuntos além dos planejamentos de aula, como a escolha de livros.

Os dados evidenciaram, nos depoimentos, a negligência e falta de incentivo e organização por parte da escola na questão de instigar e fornecer tempo para que estes professores possam proporcionar a seus estudantes um ensino que faça uma ligação entre as disciplinas e permita que os estudantes obtenham um conhecimento mais integral sobre temas como o de saúde.

\section{Incentivo para uma formação continuada dos docentes em Educação Física}

O Referencial Curricular do Paraná, um dos documentos citados pelas professoras e que visa amparar os professores para prepararem suas aulas afirma que é dever das redes de ensino junto ao Ministério da Educação e Cultura (MEC) proporcionar uma formação continuada para os docentes, visando dessa forma garantir aos estudantes um ensino e aprendizagem mais estruturado e qualificado que busca conferir significado e sentido ao mundo intelectual da escola (PARANÁ, 2018). Por esse motivo investigamos nas entrevistas se essas professoras possuíam incentivo escolar para terem uma formação continuada e um aprofundamento das questões ainda muito superficiais abordadas na escola, como o tema saúde.

As Professoras 01 e 03 se limitaram expondo apenas relações do âmbito escolar, esta na qual segundo as professoras em termos de estrutura é o suficiente, porém para se trabalhar com temas mais específicos e chamar profissionais da área da saúde para discutirem sobre essas questões desse tema, deve-se comunicar a esses profissionais que se trata de um trabalho filantrópico que visa despertar nos estudantes um interesse por essas áreas temáticas. Além disso, afirmaram ainda que a organização dessas aulas demanda tempo e trabalho devido à dificuldade de disponibilidade de horários. Conquanto percebe-se que tais professoras focaram na questão interdisciplinar e não nas questões de formação continuada, demonstrando assim uma dificuldade para compreender a questão proposta.

Conquanto as Professoras 02 e 04 afirmaram que por parte da escola é sempre bem-vindo essa formação continuada, porém o que as impede de fato é a falta de incentivo por parte do governo, pois embora este afirme no Referencial Curricular 
do Paraná que deve-se ter uma formação continuada dos profissionais da educação ele não fornece tempo na carga horária dos professores para se especializarem e darem continuidade em sua formação, pois embora os professores possuam hora atividade ela é insuficiente até mesmo para a questão de preparação das aulas e que por isso fazer um curso demanda um tempo na qual essas professoras não possuem. A Professora 02 ainda salientou que essa formação continuada, que se refere o documento, é apenas para os cursos fornecidos pelo Ministério da Educação e Cultura (MEC) para os professores e que as formações de mestrado e doutorado que esta possui são irrelevantes e são desconsideradas para a elevação no Estado e por esse motivo, carece a mesma fazer essas formações de forma conjunta ao trabalho, uma vez que a rede de ensino ao qual é concursada.

A professora 04 salientou a questão das últimas reformas do Ensino Médio terem diminuído sobremaneira as aulas de Educação Física, estas que antes eram três aulas semanais, passaram a ser duas aulas semanais. Visto que segundo Silva (2017, p. 810)

Atualmente, a Educação Física permite atividades desenvolvidas com enfoque teórico prático, as quais revitalizam o crescimento tanto intelectual quanto psicomotor do aluno, demonstrando o quanto estes processos de construção e reflexão sobre vivências e experiências estão voltados para a melhora das práticas de Educação Física na escola.

É de se indagar se poderia a Educação Física Escolar trabalhar de forma eficaz, concreta e contínua todos os conteúdos que a ela são atribuídos em apenas duas aulas semanais. Para além disso, cabe refletir também a relação de que o tratamento da saúde nas escolas, bem como os demais conteúdos é de interesse público, pois é através do exposto nas aulas que esses alunos poderão (re)avaliar seu modo de vida e procurar se prevenirem de doenças, transtornos e síndromes que podem ser acarretadas pelos modo de vida desses alunos. E em concordância com os autores Paiva et al. (2017) a educação escolar possui o dever de dar aos alunos um conhecimento aprofundado e de qualidade possibilitando assim formar cidadãos críticos que agem de forma autônoma e que visa transformar a sociedade que o cerca. Entretanto com os constantes cortes da carga horária da Educação Física Escolar seria possível oferecer isso aos discentes?

Os dados evidenciados nas entrevistas reiteram a necessidade de trazer a cena os conteúdos e competências tratados no ambiente da Educação Física Escolar carece ser revisitado de acordo com as necessidades e anseios dos estudantes, respeitando a diversidade cultural e social das escolas. Para além deste fato evidenciou-se, que embora os documentos orientadores apresentam indícios acerca da necessidade da formação continuada por vezes a prática escolar não ecoa tais ações estabelecidas e concretizadas. Conquanto ao analisar o currículo das professoras estas têm demonstrado uma busca por especialização na área da educação e mesmo demasiadamente cansativo e desgastante elas buscam essa formação continuada demonstrando que por vezes apesar dos percalços no campo da atuação ainda evidenciam-se um anseio por parte das professoras em se instrumentalizarem e se prepararem melhor para suas aulas, todavia falta-lhes tempo para tal especialização e preparação.

\section{Considerações Finais}

Visto a abrangência do tema saúde e que este também é trabalhado em outras disciplinas é imprescindível que a BNCC assim como os outros documentos orientadores reavaliem o tema saúde buscando delimitar um pouco mais quais pontos dessa temática devem ser aplicadas e que deve-se dar mais ênfase, porém sem possuir um caráter prescritivo. Além disso mostrou-se indispensável que os professores no ato de realizarem seus planejamentos busquem os documentos orientadores como um todo, visto que estes são complementares, e sempre mantenham um olhar atento para a realidade que os circundam, dessa forma torna-se-á mais fácil a elaboração de suas aula contemplando os conteúdos que são obrigatórios de acordo com os documentos curriculares abrangendo o tema saúde que consta nesses documentos e adaptem esse tema a realidade dos alunos. Cabe ainda salientar a falta de apoio e incentivo aos professores por parte das escolas para que estes 
trabalhem de forma interdisciplinar buscando oferecer uma educação mais completa para os discentes de forma que estes possam ser agentes ativos da sociedade em que vivem.

A partir dos achados dessa pesquisa, sugere-se a ampliação da pesquisa, adicionando professores de educação física de escolas públicas e particulares e realizando uma comparação entre essas instituições, para que haja um panorama acerca dessa temática no campo da educação física.

\section{Referências}

Augusto, C. A., Souza, J. P. D., Dellagnelo, E. H. L., \& Cario, S. A. F. (2013). Pesquisa Qualitativa: rigor metodológico no tratamento da teoria dos custos de transação em artigos apresentados nos congressos da Sober (2007-2011). Revista de Economia e Sociologia Rural, 51(4), 745-64

Brasil. (2018b). "Base Nacional Comum Curricular: Educação é a Base”. Versão Homologada - Educação Básica. Ministério da Educação. http://basenacionalcomum.mec.gov.br/images/BNCC_EI_EF_110518_versaofinal_site.pdf.

Brasil. (1996). Lei de Diretrizes e B. Lei nº 9.394/96, de 20 de dezembro de 1996

Castellani Filho, L. (1998). Política educacional e Educação Física: polêmicas de nosso tempo. Campinas: Autores Associados, 1998.

BRASIL. (2018). Ministério da Educação. Base Nacional Comum Curricular. Brasília. Base Nacional Comum Curricular - Educação é a Base (mec.gov.br).

Dias, J. R., A.; Souza, A. S., \& Oliveira, R. C., (2020). Physical Education and health: perspectives for high school. Revista de Saúde Coletiva, Rio de Janeiro, 30. https://www.scielo.br/j/physis/a/yckyGD56ph88FSwyNQN4T3P/?lang=en.

Ferreira, H. S., \& Sampaio, J. J. C. (2013). Tendências e abordagens pedagógicas da Educação Física escolar e suas interfaces com a saúde. EFdeportes. Buenos Aires, 18, 182.

Ferreira, H. S. (2009). Apostila para concurso de professores de Educação Física SD3: Tendências da Educação Física. Trabalho não publicado. Fortaleza.

Barreto F. E. M., \& Valente, G. S. C. (2017). Obesidade na adolescência: a interdisciplinaridade como estratégia de promoção da saúde. Pensar a Prática, 20(4).

Gil, A. C. (2002) Como elaborar projetos de pesquisa - 4. ed. - São Paulo: Atlas.

Gil, A. C. (2008). Métodos e técnicas de pesquisa social. 6. ed. Editora Atlas SA.

Monteiro, J. H. L., Queiroz, L. C., Anversa, A. L. B., \& Souza, V. F. M. (2020). O Programa Residência Pedagógica: dialética entre a teoria e a prática. HOLOS, 36, 3, 1-12.

Paiva, A. C., Oliveira, J. P., Tenório, K. M. R., Melo, M. S. T., \& Júnior, M. S. (2017). A saúde nas propostas curriculares para o ensino da educação física no Nordeste brasileiro: o que ensinar? Motricidade, 13, 2-16.. https://www.redalyc.org/pdf/2730/273052514002.pdf.

PARANÁ. (2018). Secretaria da Educação. Currículo da Rede Estadual Paranense. Curitiba. Currículo da Rede Estadual Paranaense (Crep) | Escola Digital Professor.

PARANÁ. (2018) Secretaria da Educação. Referencial Curricular do Paraná. Curitiba. Referencial Curricular do Paraná (referencialcurriculardoparana.pr.gov.br).

Penteado, F. (2009). BNCC: O que é a Base Nacional Comum Curricular e qual é o seu objetivo. https://sae.digital/bncc-o-que-e-qual-e-oseuobjetivo/\#: :text=Afinal $\% 2 \mathrm{C} \% 20 \mathrm{o} \% 20$ que $\% 20 \% \mathrm{C} 3 \% \mathrm{~A} 9 \% 20 \mathrm{a}$, Ensino $\% 20$ Fundamental $\% 20 \mathrm{e} \% 20 \mathrm{Ensino} \% 20 \mathrm{M} \% \mathrm{C} 3 \% \mathrm{~A} 9 \mathrm{dio}$.

Ramos, G. N. S., \& Ferreira, L. A. (2000). Parâmetros Curriculares Nacionais: educação física e saúde. Corpoconsciência, Santo André, 5, 55-63.

Rodrigues, A. (2019). O que é PNE?: Saiba tudo sobre o Plano Nacional de Educação. https://sae.digital/pne-plano-nacional-de-educacao/.

Santos, E. M., Barbosa, E. S., Marinho, E. F.; Araújo, L. S., \& Costa, T. O. (2016). A Educação Física no Ensino Médio: Conceitos e Perspectivas. Revista Gestão Universitária. http://www.gestaouniversitaria.com.br/artigos/aeducacao-fisica-no-ensino-medio-conceitos-e-perspectivas.

Silva, J. S., Mendonça, W. F., da Gama Bastos, L. L. A., \& Leite, S. T. (2017). O conceito de saúde e de hábitos saudáveis na escola. Pensar a Prática, 20(4).

Schuh, D. S., Goulart, M. R., Barbiero S. M., Sica, C. D., Borges, R., Moraes, D. W., \& Pellanda, L. C. (2017). Healthy School, Happy School: Design and Protocol for a Randomized Clinical Trial Designed to Prevent Weight Gain in Children. Arquivos Brasileiros de Cardiologia, $108,501-507$.

Veiga, I. P. A. (2013). A escola em debate-Gestão, projeto político-pedagógico e avaliação. Retratos da Escola, 7(12), 159-166. https://pep.ifsp.edu.br/wpcontent/uploads/2015/01/A-escola-em-debate.pdf.

Veiga, I. P. (1998). Escola: espaço do projeto político-pedagógico. Papirus Editora.https://www.sinprodf.org.br/wp-content/uploads/2014/01/PPP-segundoIlma-Passos.pdf 